\title{
ХРОНИКА
}

УДК 55:061.6

\section{Итоги работы диссертационного совета по геологическим специальностям в Пермском университете за 1993-2014 гг.}

\section{В.И. Костицын, В.А. Гершанок}

Пермский государственный национальный исследовательский университет, 614990, Пермь, ул. Букирева, 15. E-mail geophysic@psu.ru (Статья поступила в редакиию 10 февраля 2015 г.)

\begin{abstract}
Приведена информация о работе диссертационного совета по геологическим специальностям при Пермском государственном национальном исследовательском университете за 1993 - 2014 гг.

Ключевые слова: диссертационный совет, геологические специальности, Пермский университет, докторские и кандидатские диссертации.
\end{abstract}

DOI: 10.17072/psu.geol.26.91

К началу 1990-х гг. геологическая общественность Прикамья твердо сформировала мнение о необходимости создания в Пермском университете (сейчас Пермский государственный национальный исследовательский университет, ПГНИУ) докторского диссертационного совета по геологическим специальностям. К этому времени геологический факультет университета располагал высококвалифицированными кадрами профессорскопреподавательского состава. Остепененность штатных преподавателей факультета достигла $86 \%$, а кадров высшей квалификации - докторов наук, профессоров на факультете было 11, что составляло $22 \%$ общего количества преподавателей, причем 6 из них (А.К. Маловичко, В.И. Костицын, Б.К. Матвеев, Р.П. Савелов, В.А. Силаев, Б.А. Спасский) были преподавателями кафедры геофизики [1].

Проведенная в 1992 г. аттестация факультета подтвердила высокий уровень научной и учебной работы на факультете, а проводивший аттестацию профессор Казанского государственного университета 3.M. Слепак рекомендовал факультету сформировать на базе кафедры геофизики докторский диссертационный совет.

В 1993 г. решением ВАК докторский диссертационный совет в университете был открыт (приказ ВАК РФ № 247-в от 21 июля 1993 г.) и ему присвоен номер Д 063.59.02. Совету было разрешено принимать к защите докторские и кандидатские диссертации по двум специальностям:

04.00.12 - Геофизические методы поисков и разведки месторождений полезных ископаемых (геолого-минералогические и технические науки);

04.00.17 - Геология, поиски и разведка нефтяных и газовых месторождений (геолого-минералогические науки).

В совет вошли, помимо сотрудников Пермского университета, доктора наук из научных и учебных заведений Перми: 
Пермского политехнического института (сейчас Пермский национальный исследовательский политехнический университет, ПНИПУ), Горного института УрО РАН, КамНИИКИГС, ПермНИПИнефть. Совет стал первым на Западном Урале докторским диссертационным советом по названным специальностям [5]. Приведем полный состав совета того времени: 1. Костицын В.И. - председатель, д.т.н., проф., 04.00.12; 2. Савелов Р.П. - зам. председателя, д.г.-м.н., проф., 04.00.12; 3. Галкин В.И. - зам. председателя, д.г.м.н, проф., 04.00.17; 4. Гершанок В.А. ученый секретарь, к.г.-м.н., доц., 04.00.12; 5. Белоконь Т.В. - д.г.-м.н., ст. научный сотрудник, 04.00.17; 6. Дементьев Л.Ф.д.г.-м.н., проф., 04.00.17; 7. Лунев Б.С. д.г.-м.н., проф., 04.00.17; 8. Маловичко А.К. - д.Т.н., проф., 04.00.12; 9. Маловичко А.А. - д.т.н., проф., 04.00.12; 10. Матвеев Б.К. - д.г.-М.Н., проф., 04.00.12; 11. Новоселицкий В.М. - д.г.м.н., проф., 04.00.12; 12. Силаев В.А. д.т.н., проф., 04.00.12; 13. Софроницкий П.А. - д.г.-м.н., проф., 04.00.17; 14. Спасский Б.А. - д.Г.-М.Н., проф., 04.00.12; 15 . Тульбович Б.И. - д.т.н., проф., 04.00.17; 16. Шихов С.А. - д.г.-м.н., проф., 04.00.12; 17. Шурубор Ю.В. - д.г.м.н., проф., 04.00.17.

Первая защита в совете состоялась 19 мая 1994 г. Диссертацию «Повышение эффективности гравиразведки путем расширения ее технологических возможностей», представленную на соискание ученой степени доктора технических наук по специальности 04.00.12, защищал ведущий научный сотрудник Горного института УрО РАН, выпускник кафедры геофизики 1961 г. М.С. Чадаев.

В 1998 г. состав совета был увеличен до 23 человек и в него введена третья научная специальность

04.00.11 - Геология, поиски и разведка рудных и нерудных месторождений; металлогения (геолого-минералогические науки).

В связи с введением новой специальности для работы в совете были пригла- шены ведущие пермские ученые-геологи, a также профессор Уральской государственной горно-геологической академии (сейчас университет) А.Г. Баранников. По трем названным специальностям и в таком составе совет работал до 2000 г., когда Министерством образования РФ была утверждена новая номенклатура специальностей научных работников.

К этому времени в совете было защищено 19 диссертаций, из них 9 докторских и 10 кандидатских, причем 14 из них (6+ 8) - по геофизической специальности. Диссертации защищали сотрудники не только Пермского университета, но и многих других организаций (см. табл. 3).

В 2000 г. в связи с реорганизацией ВАК изменилась номенклатура научных специальностей. Это потребовало переутверждения совета для работы по требованиям вновь утвержденного «Положения о диссертационном совете». Для оптимизации перечня научных специальностей в совете было решено ввести в список специальностей по защитам новую специальность «Гидрогеология», которой ранее не было не только в Перми, но и во всем Уральском регионе. Это дало возможность привести в соответствие перечень научных специальностей в диссертационном совете с учебными специальностями обучения студентов геологического факультета Пермского университета. По предложению проректора Пермского государственного политехнического университета профессора В.И. Галкина было решено передать нефтяную специальность диссертационному совету этого университета, имеющего горно-нефтяной факультет.

Утвержденный приказом ВАК № 417в от 9 февраля 2001 г. обновленный совет из 24 человек стал проводить защиты докторских и кандидатских диссертаций по специальностям:

25.00.07 - Гидрогеология (геологоминералогические науки);

25.00.10 - Геофизика, геофизические методы поисков полезных ископаемых (геолого-минералогические и технические науки); 
25.00.11 - Геология, поиски и разведка твердых полезных ископаемых, минерагения (геолого-минералогические науки).

Следует отметить, что пополнение численного состава совета произошло в основном за счет включения в него докторов наук, защитившихся в нем ранее. В него вошли М.С. Чадаев, В.М. Проворов, В.П. Колесников, И.А. Санфиров, О.Л. Горбушина. Совет получил номер Д 212.189.01 и стал первым диссертационным советом в университете, работающим по новому Положению.

В 2008 г. совет претерпел очередную реорганизацию, в результате которой его состав был расширен до 30 человек, но по всем специальностям прием диссертаций к защите стал осуществляться только по геолого-минералогическим наукам.

В 2012 г. требования к членам совета, порядку его работы, а также к соискателям ученых степеней существенно повысились. Однако активная научная деятельность членов совета позволила им выполнить все требования ВАК, касающиеся эффективности научной работы, и численный состав совета сохранился без изменения.

Таблица1. Состав диссертационного совета Д 212.189.01 на 1 сентября 2014 г.

\begin{tabular}{|c|c|c|c|c|}
\hline $\begin{array}{l}\text { № } \\
\text { II/II }\end{array}$ & Ф. И. О., должность в совете & $\begin{array}{l}\text { Ученая } \\
\text { степень }\end{array}$ & $\begin{array}{l}\text { Специ- } \\
\text { альность } \\
\text { в совете }\end{array}$ & Основное место работы \\
\hline 1 & Костицын В.И., председатель & д. т.н. & 25.00 .10 & ПГНИУ \\
\hline 2 & Ибламинов Р.Г., зам. председателя & д.г.-м.н. & 25.00 .11 & ПГНИУ \\
\hline 3 & Катаев В.Н., зам. председателя & д.г.-м.н. & 25.00 .07 & ПГНИУ \\
\hline 4 & Гершанок В.А., ученый секретарь & д.т.н. & 25.00 .10 & ПГНИУ \\
\hline 5 & Белоконь Т.В. & д.г.-м.н. & 25.00 .11 & ПГНИУ \\
\hline 6 & Быков В.Н. & д.г.-м.н. & 25.00 .07 & ПГНИУ \\
\hline 7 & Бычков С.Г. & д.Г.-м.н. & 25.00 .10 & Горный институт УрО РАН \\
\hline 8 & Гаев А.Я. & д.Г.-м.н. & 25.00 .07 & Оренбургский госуниверситет \\
\hline 9 & Галкин В.И. & д.г.-м.н. & 25.00 .11 & ПНИПУ \\
\hline 10 & Губина А.И. & д.г.-М.н. & 25.00 .10 & ПИТЦ «Геофизика» \\
\hline 11 & Долгаль А.С. & д.ф.-м.н. & 25.00 .10 & Горный институт УрО РАН \\
\hline 12 & Дублянская Г.Н. & Д.Г.-М.Н. & 25.00 .07 & ПГНИУ \\
\hline 13 & Калинин В.Г. & д.Г.Н. & 25.00 .07 & ПГНИУ \\
\hline 14 & Колесников В.П. & д.т.н. & 25.00 .10 & ПГНИУ \\
\hline 15 & Конешов В.Н. & д.т.н. & 25.00 .10 & Институт физики Земли РАН \\
\hline 16 & Кудряшов А.И. & д.г.-м.н. & 25.00 .07 & ПНИПУ \\
\hline 17 & Лунев Б.С. & д.Г.-м.н. & 25.00 .11 & ПГНИУ \\
\hline 18 & $\begin{array}{l}\text { Матвеев Б.К. } \\
\text { (скончался в } 2014 \text { г.) }\end{array}$ & д.г.-м.н. & 25.00 .10 & ПГНИУ \\
\hline 19 & $\begin{array}{l}\text { Мягков В.Ф. } \\
\text { (скончался в } 2013 \text { г.) }\end{array}$ & д.г.-м.н. & 25.00 .11 & ПГНИУ \\
\hline 20 & Наумов В.А. & д.г.-м.н. & 25.00 .11 & ПГНИУ \\
\hline 21 & Наумова О.Б. & д.Г.-М.н. & 25.00 .07 & ПГНИУ \\
\hline 22 & Некрасов А.С. & д.г.-м.н. & 25.00 .10 & $\begin{array}{lcc}\text { Филиал } & \text { ООО } & \text { «ЛУКОЙЛ- } \\
\text { Инжиниринг» ПермНИПИнефть }\end{array}$ \\
\hline 23 & Осовецкий Б.М. & д.г.-м.н. & 25.00 .11 & ПГНИУ \\
\hline 24 & Санфиров И.А. & д.т.н. & 25.00 .10 & $\begin{array}{l}\text { Горный институт } \\
\text { УрО РАН }\end{array}$ \\
\hline 25 & Середин В.В. & д.г.-м.н. & 25.00 .07 & ПГНИУ \\
\hline 26 & Силаев В.А. & д.т.н. & 25.00 .10 & Нефтяная компания «РОСТЭК» \\
\hline 27 & Спасский Б.А. & д.г.-м.н. & 25.00 .10 & ПГНиу \\
\hline 28 & Флаасс А.С. & д.г.-м.н. & 25.00 .11 & ПНИПУ \\
\hline 29 & Чадаев М.С. & д.т.н. & 25.00 .10 & Горный институт УрО РАН \\
\hline 30 & Чайковский И.И. & д.г.-м.н. & 25.00 .11 & Горный институт УрО РАН \\
\hline
\end{tabular}


Совет по-прежнему принимал к защите докторские и кандидатские диссертации по трем названным специальностям по геолого-минералогическим наукам (приказ Министерства образования и науки РФ № 105/НК от 11 апреля 2012 г.).
Информация по составу совета на 1 сентября 2014 г. приведена в табл. 1.

С момента открытия и до 31 декабря 2014 г. в совете было защищено 62 диссертации - 18 докторских и 44 кандидатских (табл. 2).

Таблица 2. Количество защичт в совете по специиальностям

\begin{tabular}{|l|c|c|}
\hline \multicolumn{1}{|c|}{ Научная специальность } & \multicolumn{2}{|c|}{ Ученая степень } \\
\cline { 2 - 3 } & $\begin{array}{l}\text { доктора } \\
\text { наук }\end{array}$ & $\begin{array}{l}\text { кандидата } \\
\text { наук }\end{array}$ \\
\hline $\begin{array}{l}\text { 25.00.07 - Гидрогеология } \\
\text { 04.00.12; 25.00.10 - Геофизика, геофизические методы поисков полезных } \\
\text { ископаемых }\end{array}$ & - & 21 \\
\hline $\begin{array}{l}\text { 04.00.11; 25.00.11 - Геология, поиски и разведка твердых полезных ископа- } \\
\text { емых, минерагения }\end{array}$ & 4 & 7 \\
\hline $04.00 .17-$ Геология, поиски и разведка нефтяных и газовых месторождений & 3 & - \\
\hline \multicolumn{1}{|c|}{ Всего } & 18 & 44 \\
\hline
\end{tabular}

Больше половины всех защит состоялось по геофизическим специальностям 32. Причем 22 диссертации (9 докторских и 13 кандидатских) защитили выпускники кафедры геофизики. Это наглядно показывает высокую эффективность работы научной геофизической школы, созданной основателем кафедры Александром Кирилловичем Маловичко.

Перечень организаций, в которых работали соискатели, пополнился организациями из других регионов России: ТатНИПИнефть, Институт геологии Уфимского научного центра РАН, Оренбургский научный центр УрО РАН, Оренбургский государственный университет, Институт геологии и геохимии УрО РАН, Казанский федеральный университет, Южно-Российский государственный технический университет (Новочеркасский политехнический институт). В табл. 3 приведен полный перечень всех организаций, где готовились диссертации соискателей.

Кроме состоявшихся защит советом 9.09.2008 было дано положительное заключение по направленной ВАКом на дополнительное рассмотрение диссертации В.О. Волейшо, представленной на соискание ученой степени доктора геологоминералогических наук по специальности 25.00.07 - Гидрогеология.
Краткие сведения о диссертациях, защищенных в 2010-2013 гг., приведены в «Вестниках Пермского университета. Геология», выпуски: 2 (11), 2011; 1 (14), 2012; 1 (18), 2013; 1 (22), 2014 [2 - 4, 6].

В течение 2014 г. была защищена одна диссертация. Ее представила выпускница Оренбургского государственного университета Ю.М. Погосян на соискание ученой степени кандидата геологоминералогических наук по специальности 25.00.07 - Гидрогеология. Тема диссертации «Гидрогеологические исследования природно-технических систем (на примеpe района Гайского медно-колчеданного месторождения)». Научный руководитель - доктор геолого-минералогических наук, профессор кафедры геологии ФГБОУ ВПО «Оренбургский государственный университет» А.Я. Гаев. Официальные оппоненты: доктор геолого-минералогических наук, профессор кафедры прикладной экологии ФГБОУ ВПО «Российский университет дружбы народов» А.П. Хаустов; кандидат геолого-минералогических наук, заместитель генерального директора ООО «ГЕОДИН», председатель Российского союза гидрогеологов Ю.Г. Богомолов, ведущая организация ФГБОУ ВПО «Уральский государственный горный университет». Защита состоялась 26 июня 2014 г. Соискатель 
Таблица 3. Перечень организащий, где готовились диссертациии

\begin{tabular}{|c|c|c|c|c|c|c|c|c|c|}
\hline \multirow{3}{*}{$\begin{array}{l}\text { № } \\
\text { II/II }\end{array}$} & \multirow{3}{*}{ Организация } & \multicolumn{8}{|c|}{ Номенклатура специальностей и ученых степеней } \\
\hline & & \multicolumn{2}{|c|}{ 25.00.07 } & \multicolumn{2}{|c|}{$\begin{array}{l}\text { 04.00.12; } \\
25.00 .10\end{array}$} & \multicolumn{2}{|c|}{$\begin{array}{l}\text { 04.00.11; } \\
\text { 25.00.11 }\end{array}$} & \multicolumn{2}{|c|}{ 04.00.17 } \\
\hline & & Д & $\mathbf{K}$ & Д & $\mathbf{K}$ & Д & $\mathbf{K}$ & Д & $\mathbf{K}$ \\
\hline 1 & $\begin{array}{l}\text { Пермский государственный } \\
\text { университет }\end{array}$ & - & 9 & 5 & 13 & 2 & 6 & - & - \\
\hline 2 & $\begin{array}{l}\text { Горный институт } \\
\text { УрО РАН }\end{array}$ & - & - & 5 & - & - & 1 & - & - \\
\hline 3 & $\begin{array}{l}\text { Пермский } \\
\text { университет }\end{array}$ & - & - & - & - & - & - & 2 & - \\
\hline 4 & КамНИИКИГС & - & - & - & 1 & - & - & 1 & - \\
\hline 5 & ПермНИПИнефть & - & - & 1 & 3 & - & - & 1 & - \\
\hline 6 & ОАО «Пермнефтегеофизика» & - & - & 1 & 2 & - & - & - & - \\
\hline 7 & $\begin{array}{l}\text { Пермская сельскохозяйствен- } \\
\text { ная академия }\end{array}$ & - & - & 1 & - & - & - & - & - \\
\hline 8 & $\begin{array}{l}\text { Уральский государственный } \\
\text { горно-геологический универ- } \\
\text { ситет }\end{array}$ & - & 1 & 1 & 1 & - & - & - & - \\
\hline 9 & ТатНИПИнефть & - & 1 & - & - & - & - & - & - \\
\hline 10 & $\begin{array}{l}\text { Институт геологии } \\
\text { УНЦ РАН }\end{array}$ & - & 1 & - & - & 1 & - & - & - \\
\hline 11 & $\begin{array}{l}\text { Оренбургский научный центр } \\
\text { УрО РАН }\end{array}$ & - & 1 & - & - & - & - & - & - \\
\hline 12 & $\begin{array}{l}\text { Институт геологии и геохимии } \\
\text { УрО РАН }\end{array}$ & - & - & - & - & 1 & - & - & - \\
\hline 13 & $\begin{array}{l}\text { Казанский государственный } \\
\text { университет }\end{array}$ & - & 1 & - & - & - & - & - & - \\
\hline 14 & $\begin{array}{l}\text { Южно-Российский государ- } \\
\text { ственный технический уни- } \\
\text { верситет }\end{array}$ & - & 2 & - & - & - & - & - & - \\
\hline \multirow[t]{2}{*}{15} & $\begin{array}{l}\text { Оренбургский государствен- } \\
\text { ный университет }\end{array}$ & - & 1 & - & - & - & - & - & - \\
\hline & В С Е Г О & - & 16 & 11 & 21 & 4 & 7 & 3 & - \\
\hline
\end{tabular}

Примечание. Некоторые диссертации были подготовлены в двух организациях.

обосновала применение барьерных технологий и модульных принципов оценки состояния вод. Теоретическая значимость работы заключается в доказательстве взаимосвязи защищенности подземных вод и вертикальной гидрогеологической нальности. Практическая значимость состоит в предложенных рекомендациях по минимизации техногенной нагрузки на подземные воды на основе применения барьерных технологий.

Таким образом, за более чем 20 лет, прошедших с момента первой защиты диссертации, совет стал хорошей кузницей научных кадров для учебных, научных и производственных организаций многих регионов России.
В связи с переаттестацией диссертационных советов полномочия совета заканчиваются 21 мая 2015 г. (приказ Минобрнауки РФ № 668/нк от 21 ноября 2014 г.). Для возобновления защит диссертаций по геологическим специальностям будет подготовлено ходатайство об открытии нового диссертационного совета.

\section{Библиографический список}

1. Гершанок B.A. Основные этапы развития геологического факультета // 70 лет геологическому факультету Пермского университета: юбилейный сб. ст. / Перм. гос. унт. Пермь, 2001. С. 6 - 46.

2. Гершанок В.А., Костищын В.И. О защите диссертаций по геологии в 2011 году в со- 
вете Д 212.189.01 при Пермском университете // Вестник Пермского университета. Геология. 2012. Вып. 1 (14). С. 96-100.

3. Гершанок В.А., Костицын В.И. О защите диссертаций по геологии в 2012 году в совете Д 212.189.01 при Пермском университете // Вестник Пермского университета. Геология. 2013. Вып. 1 (18). С. 91-94.

4. Гершанок В.А., Костицын В.И. О защите диссертаций по геологическим специальностям в 2013 году в совете Д 212.189.01 при Пермском государственном национальном исследовательском университете
// Вестник Пермского университета. Геология. 2014. Вып. 1 (22). С. 89-93.

5. Костищын В.И. Диссертационные советы по геологическим специальностям в ПГУ // Геологический факультет Пермского университета - три четверти века: юбил. сб. / Перм. гос. ун-т. Пермь, 2006. С. 4567.

6. Костицын В.И., Гершанок В.А. О работе диссертационного совета при Пермском государственном университете по геологическим специальностям в 2010 году // Вестник Пермского университета. Геология. 2011. Вып. 2 (11). С. 96-101.

\title{
Summary of Activity of the Dissertation Committee on Geological Sciences at Perm State University From 1993 Until 2014
}

\author{
V.I. Kostitsyn, V.A. Gershanok \\ Perm State University, 15 Bukireva Str., Perm, 614990, Russia E-mail: geophys- \\ ic@psu.ru \\ Information about activity of the Dissertation Committee on Geological Sciences at \\ Perm State University from 1993 until 2014 is presented. \\ Keywords: Dissertation Committee; geological program; Perm University; doctorate \\ and candidate dissertations.
}

\section{References}

1. Gershanok V.A. 2001. Osnovnye etapy razvitiya geologicheskogo fakulteta [General stages of evolution of the Geological Faculty]. 70-th anniversary of Geological Faculty of the Perm University, Jubilee volume. Perm Univ., pp. 6-46. (in Russian)

2. Gershanok V.A., Kostitsyn V.I. 2012. O zashchite dissertatsiy po geologii v 2011 godu v sovete D 212.189.01 pri Permskom universitete [About the defense of dissertations in geology in 2011 in the Commithee D 212.189.01 of the Perm University]. Vestnik Permskogo universiteta. Geologiya. 1 (14): 96-100. (in Russian)

3. Gershanok V.A., Kostitsyn V.I. 2013. O zashchite dissertatsiy po geologii v 2012 godu v sovete D 212.189.01 pri Permskom universitete [About the defense of dissertations in geology in 2012 in Committee D 212.189.01 of the Perm University]. Vestnik Permskogo universiteta. Geologiya. 1 (18): 91-94. (in Russian)
4. Gershanok V.A., Kostitsyn V.I. 2014. O zashchite dissertatsiy po geologicheskim spetsialnostyam v 2013 godu v sovete D 212.189.01 pri Permskom gosudarstvennom natsionalnom issledovatelskom universitete [About the defense of dissertations in geology in 2013 in Committee D 212.189.01 of the Perm University. Vestnik Permskogo universiteta. Geologiya. 1 (22): 89-93. (in Russian)

5. Kostitsyn V.I. 2006. Dissertatsionnye sovety po geologicheskim spetsialnostyam v PGU [PSU Dissertation Committees in Geology]. In Geological Faculty of Perm University three quarters of a Century. Jubilee volume. Perm Univ., Perm, pp. 45-67. (in Russian)

6. Gershanok V.A., Kostitsyn V.I. 2011. O rabote dissertatsionnogo soveta pri Permskom gosudarstvennom universitete po geologicheskim spetsialnostyam v 2010 godu [About activity of the Dissertation Committee in geology of the Perm State University in 2010. Vestnik Permskogo universiteta. Geologiya. 2 (11): 96-101. (in Russian) 